\title{
Proliferation rate of colonic mucosa in normal subjects and patients with colonic neoplasms: a refined immunohistochemical method
}

\author{
J W M Welberg, E G E de Vries, M J Hardonk, N H Mulder, G Harms, J Grond,
} N Zwart, J Koudstaal, L de Ley, J H Kleibeuker

\begin{abstract}
An increased colonic epithelial proliferation rate and an increase of the cryptal proliferative zone are probable markers of increased susceptibility to colonic cancer. In this study an immunohistochemical method using 5-bromodeoxyuridine (BrdUrd) to measure the proliferation rate of colonic mucosa in vitro was used. Fresh endoscopic colonic biopsy specimens were incubated with BrdUrd and then processed for immunohistochemistry using a monoclonal antibody. Essential procedures with respect to the equal distribution of nuclei stained with BrdUrd in the biopsy specimens proved to be the cutting of the specimens before incubation and the use of a microwave oven at the beginning of incubation. The use of the procedure of the running average showed that 12 length cut crypts are sufficient to determine reliably the proliferation rate, expressed as the labelling index (LI). This was determined in the biopsy specimens of 10 subjects without organic colonic disease, eight patients with adenomatous colonic polyps, and in six patients with (recent) colonic carcinoma. Mean LI in the controls was significantly lower than in patients with colonic polyps and in those with colon cancer.

It is concluded that this method is promising for screening persons at risk for colon cancer and will be of great potential in performing dietary intervention studies in these subjects.
\end{abstract}

Cancer of the colon is common in the western world and is an important cause of morbidity and mortality. To decrease the incidence of this tumour it is important to identify those at increased risk of developing it. In several studies it has been shown that patients with neoplastic colonic disease have an increased proliferation rate of their colonic mucosa. ${ }^{1-3}$ Such an increase in subjects without tumours might indicate an increased risk for the development of colonic cancer, as is suggested by studies in family members of patients with polyposis coli and familial non-polyposis colon cancer. ${ }^{45}$ It has also been shown that this increased proliferation rate can be reduced by dietary intervention. ${ }^{6-8}$ The autoradiographical method with ${ }^{3} \mathrm{H}$-thymidine to measure mucosal proliferation rate is well accepted, but it is time consuming and radioactive. $^{258}$ We therefore developed an immunohistochemical method using 5bromo-deoxyuridine (BrdUrd) to measure the proliferation rate of colonic mucosa. BrdUrd is a pyrimidine analogue of thymidine and has been shown to be incorporated in the DNA of normal and malignant cells after in vivo administration. ${ }^{910}$

In this study we describe our methodology to measure the proliferation rate of colonic mucosa in vitro using immunohistochemistry in normal controls and patients with colonic neoplasms. This study was performed using normal looking colonic mucosa, which is especially important in view of the potential use of this method for identification of high risk patients and in dietary intervention studies.

\section{Methods}

Biopsy specimens of endoscopically normal looking colonic mucosa were taken at $30 \mathrm{~cm}$ from 10 healthy subjects (six men, four women, mean age 44.5 years, range 17 to 75 years) who underwent diagnostic sigmoidoscopy and who were found not to have organic colonic disorders. In all these patients a barium enema and histological examination of the biopsy specimens yielded normal results. Biopsy specimens of endoscopically normal looking colonic mucosa were taken at $30 \mathrm{~cm}$ from 14 patients (nine men, five women, mean age 68.7 years, range 47 to 85 years) who had one or more adenomatous colonic polyps or a colon carcinoma, or who had undergone surgery for colon carcinoma in the recent past. The polyps were located in the sigmoid colon and the tumours were localised throughout the whole colon and in the sigmoid. The size of the polyps ranged from 3 to $45 \mathrm{~mm}$.

Immediately after sigmoidoscopy the biopsy specimens were placed in Hanks's

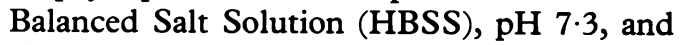
shaken gently for five minutes to remove the mucus remnants from the mucosal surface. The biopsy specimens were cut in two or more small pieces $\left(1-2 \mathrm{~mm}^{3}\right)$ to obtain an optimal diffusion of BrdUrd (Serva, Heidelberg, West Germany) into the tissue. They were incubated in $5 \mathrm{ml}$ HBSS with $10 \%$ fetal calf serum (Dakopatts, Copenhagen, Denmark) and $500 \mu \mathrm{M}$ BrdUrd. This solution was heated in a microwave oven ( $M$ 690; Miele, Vianen, The Netherlands) for seven seconds at 700 Watts to about $32^{\circ} \mathrm{C}^{11}$ before 
incubation in a waterbath at $37^{\circ} \mathrm{C}$. Incubation for one and a half hours was found to be optimal. Biopsy specimens were then frozen in TissueTek II (ICN Biochemicals Ltd., Buckinghamshire) in freon at $-80^{\circ} \mathrm{C}$. Frozen sections $(4 \mu \mathrm{m})$ were cut on a cryostat (Leitz 1720 digital, Wetzlar, West Germany) and put on slides. Sections $(4 \mu \mathrm{m})$ were screened under the microscope directly after cutting. Only sections with one or more length cut crypts were stored at $-20^{\circ} \mathrm{C}$ and used for further processing. After fixation for $10 \mathrm{~min}$ utes in Carnoy's fixative (ethanol, chloroform, glacial acetic acid, 6:3:1), sections were washed in ethanol $96 \%$, twice for one and a half minutes each, ethanol $50 \%$ (two minutes) and distilled water (two minutes). Sections were rinsed in $1 \mathrm{~N} \mathrm{HCl}$ for one minute at room temperature, hydrolysed in one $\mathrm{N} \mathrm{HCl}$ for 15 minutes at $60^{\circ} \mathrm{C}$, rinsed in $1 \mathrm{~N} \mathrm{HCl}$ for one minute at room temperature and washed in phosphate buffered saline (PBS, 8.75 g $\mathrm{NaCl}, 1.37 \mathrm{~g} \mathrm{Na}_{2} \mathrm{PO}_{4}$, and $0.215 \mathrm{~g} \mathrm{KH}_{2} \mathrm{PO}_{4}$, dissolved in 1 litre of distilled water), $\mathrm{pH} 7 \cdot 4$, with refreshment of PBS after one and a half, three, and five minutes.

\section{IMMUNOHISTOCHEMISTRY}

The DNA incorporated BrdUrd was visualised immunohistochemically according to the method of Harms et al. ${ }^{12}$ Sections were incubated with $35 \mu \mathrm{l}$ undiluted tissue culture supernatant containing anti-BrdUrd mouse monoclonal antibody for 30 minutes at room temperature and subsequently washed with PBS, pH 7.4. The use of Carnoy's fixative obviated the need for inhibiting endogenous peroxidase activity. The sections were incubated for 15 minutes with peroxidase conjugated rabbit anti-mouse antibody (Dakopatts, Copenhagen, Denmark) at a dilution of 1:20 in PBS, $\mathrm{pH} 7 \cdot 4$, containing $5 \%$ normal rat serum after washing in PBS. The reaction product was visualised using 3-amino-9ethyl-carbazole (AEC, EGA-Chemie, Steinheim/Albuch, West Germany) as a chromogen for 10 minutes. The unlabelled nuclei were counterstained with celestin blue 66 (Gurr, BDH Chemicals Ltd, Poole, Dorset) for six and a half minutes and Mayer's haematoxylin (Sigma, St Louis, Missouri) for 10 minutes, to facilitate distinguishing one cell from another. After counterstaining, the slides were blued in running tap water and mounted in Kaiser's glycerin-gelatin (Merck, Darmstadt, West Germany).

\section{ANALYSIS}

The mucosal proliferation rate was expressed as the labelling index (LI). To obtain the LI the number of labelled nuclei, divided by the total number of nuclei $\times 100(\%)$, was determined in a number of individual crypts. The average of these individual values was defined as the LI. For this calculation only length cut crypts, containing at least 35 cells per crypt column, were used, as previously described by Terpstra et al. ${ }^{2}$ Care was taken not to use serial sections in assessing LI so as to prevent counting the same crypts more than once.
Because length cut crypts are limited, the minimal number of crypts necessary to obtain a reliable LI was determined. For this we calculated the so-called running average in the biopsy specimens of all subjects - that is, the minimal number of crypts required to obtain a constant average value of the percentages of labelled nuclei in individual crypts.

Comparison of LI of normal subjects and patients with neoplasms was made using Student's $t$ test for unpaired results. Differences were considered to be significant at $p<$ 0.05 .

\section{Results}

Equal distribution of the BrdUrd in the biopsy specimens proved to be a problem. This was solved by a combination of procedures. First, when the muscularis mucosae was in situ in the biopsy specimen, equal distribution was not always obtained. Specimens were therefore cut in several small pieces before incubation with BrdUrd. A second important factor was the BrdUrd concentration; $500 \mu \mathrm{M}$ BrdUrd was the lowest concentration at which optimal staining was obtained. Finally, the use of a microwave oven in heating the biopsy specimens in solution before incubation resulted, using the method described here, in a consistent equal distribution of stained nuclei in all biopsy specimens (figs 1 and 2).

The fixation method using Carnoy fixative was the only one that resulted in both good staining of the BrdUrd labelled cells and good morphological detail of all cells labelled as well as unlabelled. The morphological quality is essential to distinguish individual cells to determine the $\cdot \mathbf{L I}$. Counterstaining with haematoxylin alone was not sufficient. Only in combination with celestin blue was the con-

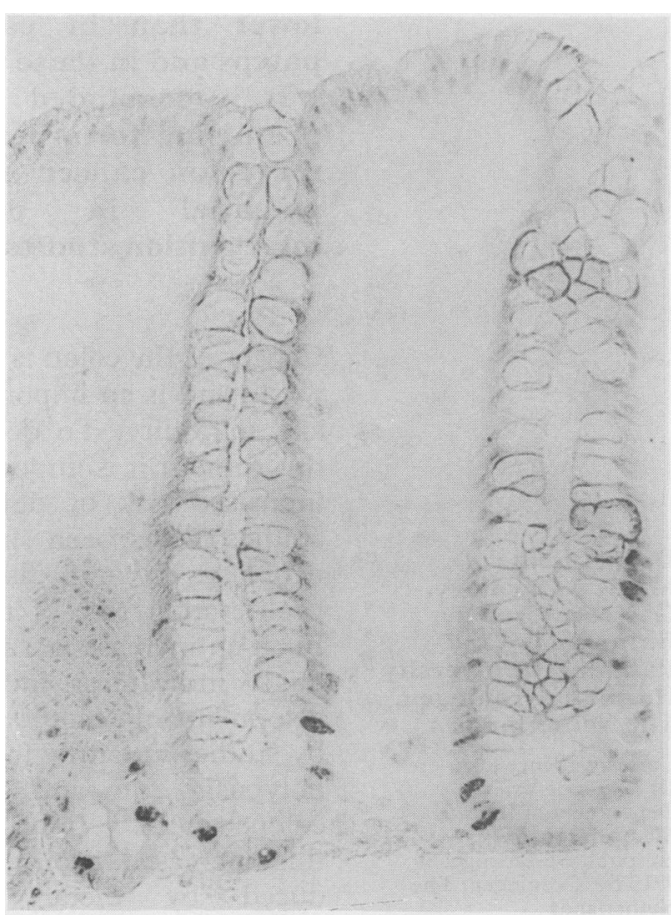

Figure 1 Colonic mucosa from a patient without colonic disease with an LI of $6.45 \%$. 
Figure 2 Normal looking colonic mucosa from a patient with colonic carcinoma with an $L I$ of $15 \cdot 3{ }^{\circ}$.

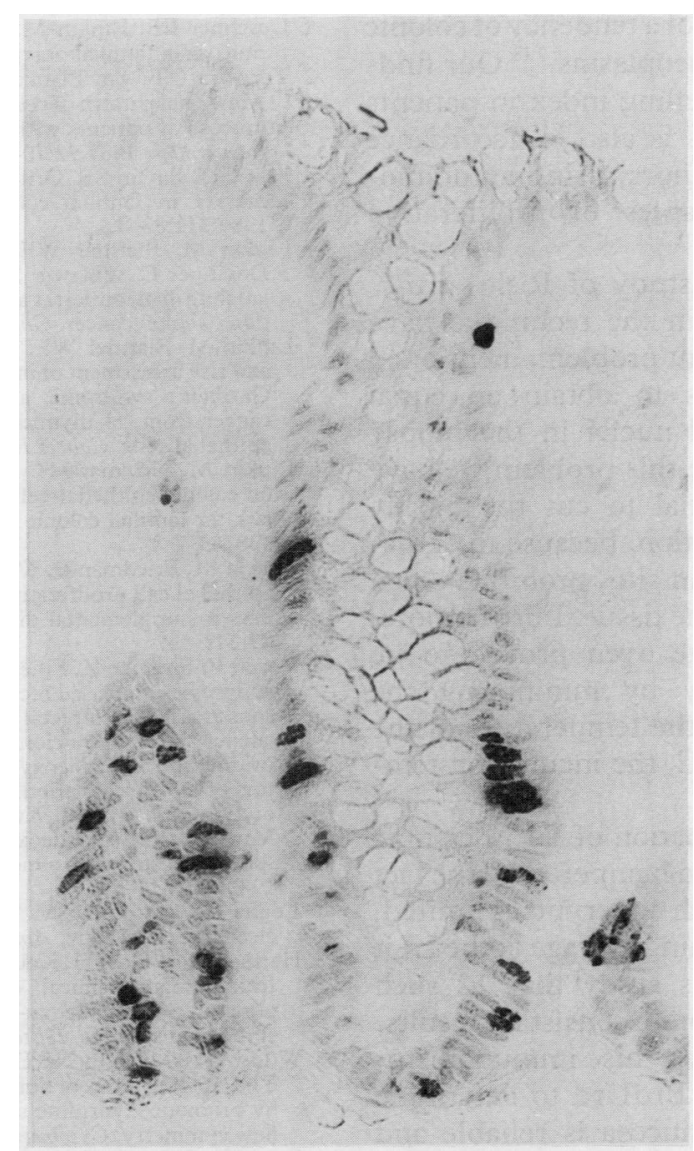

trast such that each cell could be distinguished separately. Because of the good morphology in frozen sections, there was no need for more time consuming paraffin wax embedded sections.

After counting 12 crypts the mean LI did not change when more than those 12 were counted (fig 3).

Mean (SEM) labelling index in the control subjects was $5.9(0.4) \%$. Mean (SEM) LI in the patients with colonic polyps was $8 \cdot 2(0 \cdot 4) \%$ and in patients with colon cancer it was $10 \cdot 1$ $(1.4)^{\circ} \%$, which were both significantly higher than LI in the controls $(p<0.01)$. The LI of both patient groups were not significantly different (fig 4). The table shows the LI in normal and patient groups, separated in the upper, middle, and lower third of the crypts. Between normal and patient groups there was no significant difference in LI in the upper part of the colonic crypts, but there was a significant difference in the lower part and in the middle part.

\section{Discussion}

In 1983 Morstyn et al showed extensive incorporation of BrdUrd into normal skin, normal bone marrow, and malignant melanoma cells with a monoclonal antibody. ${ }^{10}$ Numerous investigators have since shown that BrdUrd is

Mean (SEM) LI in upper, middle, and lower parts of colonic crypts

\begin{tabular}{llll}
\hline & Upper third & Middle third & Lower third \\
\hline Normal subjects & $1.01(0.38)$ & $5.03(0.60)(a)$ & $10 \cdot 79(1.34)(\mathrm{d})$ \\
Patients with colonic polyps & $1.57(0.42)$ & $7.48(0.69)(\mathrm{b})$ & $14.81(1.46)$ \\
Patients with colon carcinoma & $1.38(1 \cdot 15)$ & $9.06(1.34)(\mathrm{c})$ & $18.28(3.78)(\mathrm{e})$ \\
\hline
\end{tabular}

a $v$ b: $\mathrm{p}<0.02 ;$ a $v$ c: $\mathrm{p}<0.01 ; \mathrm{d} v$ e: $\mathrm{p}<0.05$.

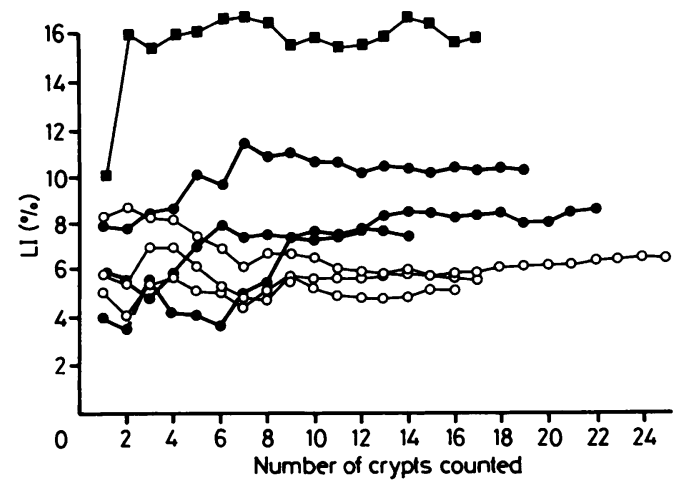

Figure 3 Running average of LI in normal looking colonic mucosa of seven subjects; three normal controls $(\mathrm{O})$, three with colonic polyps ( ) and one with colon carcinoma ( $)$.

equivalent to ${ }^{3} \mathrm{H}$-thymidine for labelling proliferating cells in a variety of tissues. ${ }^{13-16}$ The results of the method are comparable with those of the autoradiographical method, ${ }^{258}$ and they extend the findings of Risio et al, ${ }^{17}$ who also described a methodology using BrdUrd to determine mucosal proliferation rate in vitro in colonic biopsy specimens. The immunohistochemical method with BrdUrd has some important advantages compared with the autoradiographical method with ${ }^{3} \mathrm{H}$-thymidine. First, it is less time consuming: whereas autoradiography generally takes several weeks, with the immunohistochemical method the results can be obtained within two days. Another important advantage is that no radioactivity is required when using BrdUrd. The two techniques have in common that it is possible to study the distribution of the labelled cells over the crypt, which contrasts with other methods for determination of mucosal proliferative activity. This is an important property, particularly as an altered distribution of proliferating cells may well be the most

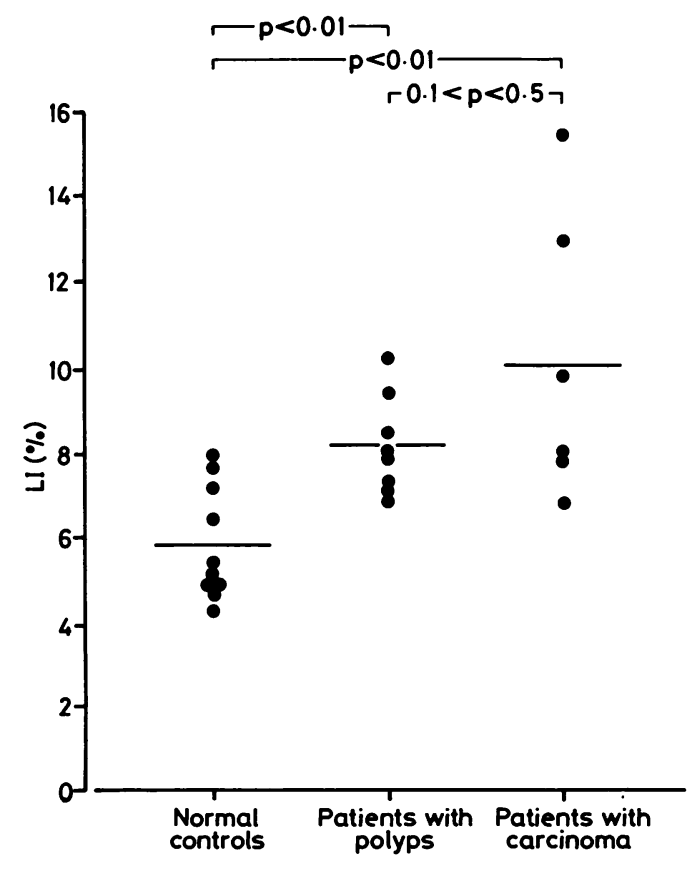

Figure 4 Individual labelling indexes of normal looking colonic mucosa in normal subjects $(n=10)$, patients with colonic polyps $(n=8)$, and patients with colon carcinoma $(n=6)(-=$ mean labelling index $)$. 
pronounced expression of a tendency of colonic mucosa to give rise to neoplasms. ${ }^{718}$ Our finding of an increased labelling index in patients with colonic neoplasms is also in accordance with those of other authors, using autoradiography or other variables of proliferation rate. $^{1-3}$

Compared with the study of Risio et $a l,{ }^{17}$ several improvements in the technique have been made. An important problem, mentioned by those authors, was to obtain an equal distribution of labelled nuclei in the biopsy specimen. To overcome this problem we have found that it is essential to cut the biopsy specimen before incubation, because the muscularis mucosae, when in situ, prohibits equal BrdUrd diffusion into the tissue. Furthermore, the use of a microwave oven proved to be advantageous, probably by minimising the time necessary to raise the temperature of the biopsy specimen to $37^{\circ} \mathrm{C}$, the incubation temperature.

The reliable determination of LI in colonic biopsy specimens is often hampered by the fact that the number of length cut crypts is limited. By determining the running average of the $\mathrm{LI}$ it has been shown in this study that 12 such crypts are sufficient to obtain consistent results.

It is concluded that this immunohistochemical method using BrdUrd to determine LI in human colonic mucosa is reliable and time sparing. It is a promising technique for screening persons at risk for colon cancer and may also be of great potential in performing dietary intervention studies in these subjects.

This study was approved by the Medical Ethical Committee of the University Hospital Groningen.

We thank J T Winter and B Biesma for participating in the development of the described immunohistochemical method. This study was supported in part by a grant from the J K de This study was supported in part by a grant from the J K de GUKC 89-08.
1 Deschner EE, Lipkin M. Proliferative patterns in colonic mucosa in familial polyposis. Cancer 1975;35:413-8.

2 Terpstra OT, van Blankenstein M, Dees J, Eilers GAM. Abnormal pattern of cell proliferation in the entire colonic mucosa of patients with colon adenoma or cancer. Gastroenterology 1987;92:704-8.

3 Luk GD, Baylin SB. Omithine decarboxylase as a biologic marker in familial colonic polyposis. $N$ Engl J Med 1984;311:80-3.

4 Lipkin M, Blattner WE, Fraumeni Jr JF, Lynch HT, Deschner E, Winawer S. Tritiated thymidine $(0 \mathrm{p}, 0 \mathrm{~h})$ labeling distribution as a marker for hereditary predisposilabeling distribution as a marker for hereditary predisp
tion to colon cancer. Cancer Res 1983;43:1899-904.

5 Lipkin M, Blattner WE, Gardner EJ, et al. Classification and risk assessment of individuals with familial polyposis, Gardner's syndroma, and familial non-polyposis colon cancer from ${ }^{3} \mathrm{H}$-thymidine labelling patterns in colonic epithelial cells. Cancer Res 1984;44:4201-7.

6 Lipkin M, Newmark H. Effect of added dietary calcium on colonic epithelial-cell proliferation in subjects at high risk for familial colonic cancer. $N$ Engl J Med 1985;313: 1381-4.

7 Lipkin M, Friedman E, Winawer SJ, Newmark H. Colonic epithelial cell proliferation in responders and nonresponders to supplemental dietary calcium. Cancer Res 1989; 49:248-54.

8 Rozen P, Fireman Z, Fine N, Wax Y, Ron E. Oral calcium suppresses increased rectal epithelial proliferation of persons at risk of colorectal cancer. Gut 1989;30:650-5.

9 Gratzner HB. Monoclonal antibody to 5-bromodeoxyuridine and 5-iododeoxy-uridine: a new reagent for detection of DNA replication. Science 1982;218:474-5.

10 Morstyn G, Hsu S-M, Kinsella T, Gratzner H, Russo A, Mitchell JB. Bromodeoxyuridine in tumors and chromosomes detected with a monoclonal antibody. J Clin Invest 1983;72:1844-50.

11 Login GR, Dvorak AM. Microwave energy fixation for electron microscopy. Am J Pathol 1985;120:230-43.

12 Harms G, van Goor H, Koudstaal J, de Ley L, Hardonk MJ. Immunohistochemical demonstration of DNA-incorporated 5-bromodeoxy-uridine in frozen and plastic embedded sections. Histochemistry 1986;85:139-43.

13 Wilson GO, McNally NJ, Dunphy E, Kärcher H, Pfagner R. The labeling index of human and mouse tumours assessed by bromodeoxyuridine staining in vitro and in vivo and flow cytometry. Cytometry 1985;6:641-7.

14 Sasaki K, Ogino T, Takahashi M. Immunological determination of labeling index on human tumor tissue sections using monoclonal anti-BrdUrd antibody. Stain Technol 1986;61:155-61.

15 Morstyn G, Pyke K, Gardner J, Ashcroft R, de Fazio A, Bhathal P. Immunohistochemical identification of proliferating cells in organ culture using bromodeoxyuridine liferating cells in organ culture using bromodeoxyuridine and a monoclor

16 Risio M, Coverlizza S, Poccardi G, Candelaresi GL, Gaiola $O$. In vitro immunohistochemical localization of $S$-phase cells by a monoclonal antibody to bromodeoxyuridine. Bas Appl Histochem 1986;30:469-77.

17 Risio M, Coverlizza S, Ferrari A, Candelaresi GL, Rossini FP. Immunohistochemical study of epithelial cell proliferation in hyperplastic polyps, adenomas, and adenocarcinomas of the large bowel. Gastroenterology 1988;94: 899-906.

18 Ponz de Leon $M$, Roncucci $L$, DiDonato $\mathrm{P}$, et al. Pattern of epithelial cell proliferation in colorectal mucosa of normal subjects and of patients with adenomatous polyps or cancer of the large bowel. Cancer Res 1988;48:4121-6. 